\title{
Pathogenesis of Acute Respiratory Distress Syndrome
}

\author{
${ }^{1}$ Department of Medicine, University of California, San Francisco, \\ San Francisco, California \\ 2 Department of Medicine, Cardiovascular Research Institute, \\ University of California, San Francisco, San Francisco, California \\ 3 Department of Anesthesia, Cardiovascular Research Institute, \\ University of California, San Francisco, San Francisco, California \\ ${ }^{4}$ Division of Allergy, Pulmonary, and Critical Care Medicine, \\ Department of Medicine, Vanderbilt University School of Medicine, \\ Nashville, Tennessee
}

Laura A. Huppert, MD ${ }^{1}$ Michael A. Matthay, MD ${ }^{2,3}$ Lorraine B. Ware, MD

Semin Respir Crit Care Med 2019;40:31-39.

\author{
Address for correspondence Lorraine B. Ware, MD, T1218 Medical \\ Center North, 1161 21st Avenue S, Nashville, TN 37232-2650 \\ (e-mail: lorraine.ware@vumc.org).
}

\begin{abstract}
Keywords

- acute respiratory distress syndrome

- alveolar fluid clearance

- vectorial ion transport

- pulmonary edema

- mesenchymal stromal cells

Acute respiratory distress syndrome (ARDS) is a syndrome of acute respiratory failure caused by noncardiogenic pulmonary edema. Despite five decades of basic and clinical research, there is still no effective pharmacotherapy for this condition and the treatment remains primarily supportive. It is critical to study the molecular and physiologic mechanisms that cause ARDS to improve our understanding of this syndrome and reduce mortality. The goal of this review is to describe our current understanding of the pathogenesis and pathophysiology of ARDS. First, we will describe how pulmonary edema fluid accumulates in ARDS due to lung inflammation and increased alveolar endothelial and epithelial permeabilities. Next, we will review how pulmonary edema fluid is normally cleared in the uninjured lung, and describe how these pathways are disrupted in ARDS. Finally, we will explain how clinical trials and preclinical studies of novel therapeutic agents have further refined our understanding of this condition, highlighting, in particular, the study of mesenchymal stromal cells in the treatment of ARDS.
\end{abstract}

Acute respiratory distress syndrome (ARDS) is a syndrome of acute respiratory failure caused by noncardiogenic pulmonary edema. The most common clinical disorders associated with the development of ARDS are bacterial and viral pneumonia. ARDS is also commonly caused by sepsis due to nonpulmonary sources, severe trauma, and aspiration of gastric contents, and less commonly by pancreatitis and drug reactions. ${ }^{1}$ Criteria for the diagnosis for ARDS have changed over time; the current definition includes acute onset of impaired oxygenation (arterial hypoxemia with $\mathrm{PaO}_{2} / \mathrm{FiO}_{2}$ ratio $<300 \mathrm{~mm} \mathrm{Hg}$ ) and bilateral infiltrates on chest imaging in the absence of left atrial hypertension as the dominant cause of pulmonary edema. ${ }^{2}$ Based on the Berlin definition, ARDS is divided into three categories of severity depending on the degree of hypoxemia: mild $\left(\mathrm{PaO}_{2} /\right.$ $\left.\mathrm{FiO}_{2} 200-300 \mathrm{~mm} \mathrm{Hg}\right)$, moderate $\left(\mathrm{PaO}_{2} / \mathrm{FiO}_{2} 100-200 \mathrm{~mm} \mathrm{Hg}\right)$, and severe $\left(\mathrm{PaO}_{2} / \mathrm{FiO}_{2}<100 \mathrm{~mm} \mathrm{Hg}\right){ }^{2}$ The prevalence of ARDS in the United States is 5 to 35 cases $/ 100,000$ individuals annually, depending on the definitions utilized and study methodology. ${ }^{3}$ The mortality of ARDS is 25 to $40 \%$ in most studies. ${ }^{4,5}$ Despite five decades of basic and clinical research, there is still no effective pharmacotherapy for this syndrome and the treatment remains primarily supportive with lung protective ventilation and a conservative fluid management strategy. Therefore, it is critical to study the pathogenesis and pathophysiology of ARDS to identify novel targeted therapies for this condition.

ARDS is a complex clinical syndrome with a heterogeneous clinical phenotype, which has made it more challenging to study. Nonetheless, since the first description of ARDS in $1967,{ }^{6}$ advances in laboratory and clinical studies have yielded valuable insights into the mechanisms responsible for the pathogenesis and pathophysiology of this condition.
Issue Theme Acute Respiratory Distress Syndrome: Evolving Concepts; Guest Editors: Greg S. Martin, MD, MSc, and Jordan A. Kempker, MD, MSc
Copyright (c) 2019 by Thieme Medical Publishers, Inc., 333 Seventh Avenue, New York, NY 10001, USA. Tel: +1(212) 584-4662.
DOI https://doi.org/ 10.1055/s-0039-1683996. ISSN 1069-3424. 
When the lung is injured by infection, trauma, or inflammatory conditions, inflammatory pathways are activated. The inflammatory response can aid in pathogen clearance, but excess inflammation can also contribute to alveolar damage -specifically greater endothelial and epithelial permeabilities-resulting in the accumulation of protein-rich alveolar edema fluid. Once pulmonary edema fluid accumulates in the interstitium and air spaces of the lungs, it causes increased work of breathing and impaired gas exchange resulting in hypoxemia, reduced carbon dioxide excretion, and ultimately acute respiratory failure. In uninjured lungs, active ion transport across the alveolar epithelium creates an osmotic gradient that drives alveolar fluid clearance (AFC). ${ }^{7}$ However, in ARDS, the osmotic gradient is disrupted and AFC is reduced, further compounding the decreased capacity to remove edema fluid from the distal airspaces of the lung.

In this review, we will first describe how increased inflammation causes endothelial and epithelial permeabilities, ultimately resulting in the accumulation of pulmonary edema fluid. Second, we will explain why AFC is reduced in this condition, highlighting key molecular pathways involved. Finally, we will summarize how clinical trials and the study of novel therapeutics offer further insight into ARDS pathophysiology.

\section{Pathogenesis of ARDS: Excess Inflammation, Endothelial, and Epithelial Permeabilities}

There are several pathophysiologic derangements that are central to the development of ARDS, including dysregulated inflammation and increased lung endothelial and epithelial permeabilities. Initially, acute lung injury is driven by dysregulated inflammation. Microbial products or cell injury-associated endogenous molecules (danger-associated molecular patterns) bind to Toll-like receptors on the lung epithelium and alveolar macrophages and activate the innate immune system. ${ }^{8}$ Mechanisms of innate immune defense, such as the formation of neutrophil extracellular traps and histone release, can be beneficial in capturing pathogens but may worsen alveolar injury. ${ }^{9}$ The immune system also generates reactive oxygen species, leukocyte proteases, chemokines, and cytokines that help neutralize pathogens, but can also result in worsening lung injury. ${ }^{10}$ In essence, there is a delicate balance between effective immune activation to combat infection and excessive or dysregulated activation that contributes to alveolar injury.

In addition to excessive inflammation in ARDS, another central pathophysiologic derangement is the disruption of the lung microvascular barrier due to increased endothelial and epithelial permeabilities (-Fig. 1A, B). In healthy lungs, endothelial stabilization is mediated by vascular endothelial cadherin (VE-cadherin), which is an endothelial-specific adherens junction protein that is required for to maintain endothelial barrier integrity in lung microvessels. ${ }^{11}$ During lung injury, increased concentrations of thrombin, tumor necrosis factor- $\alpha$ (TNF- $\alpha$ ), vascular endothelial growth factor, and leukocyte signals in the lungs destabilize the VEcadherin bonds, resulting in increased endothelial permeability and the accumulation of alveolar fluid. ${ }^{12}$ The importance of VE-cadherin bonds has been confirmed in mouse models. Specifically, alveolar fluid accumulates in a mouse model of lipopolysaccharide (LPS)-induced lung injury, but when the VE-cadherin bonds are stabilized by genetic alterations that prevent breakdown or by blocking VE phosphodiesterase, there is reduced edema formation. ${ }^{13,14}$ In sum, the inflammatory-induced damage to lung endothelium results in increased capillary permeability, and thus leads to pulmonary edema formation.

In addition to endothelial permeability, lung epithelial permeability is also an important factor in ARDS pathogenesis. ${ }^{15,16}$ The alveolar epithelial barrier is similar to its endothelial counterpart but has E-cadherin junctions instead of VE-cadherin junctions, and it is substantially less permeable. Under pathologic conditions, neutrophil migration causes epithelial injury by disrupting intercellular junctions and causing apoptosis and denudation, ultimately resulting
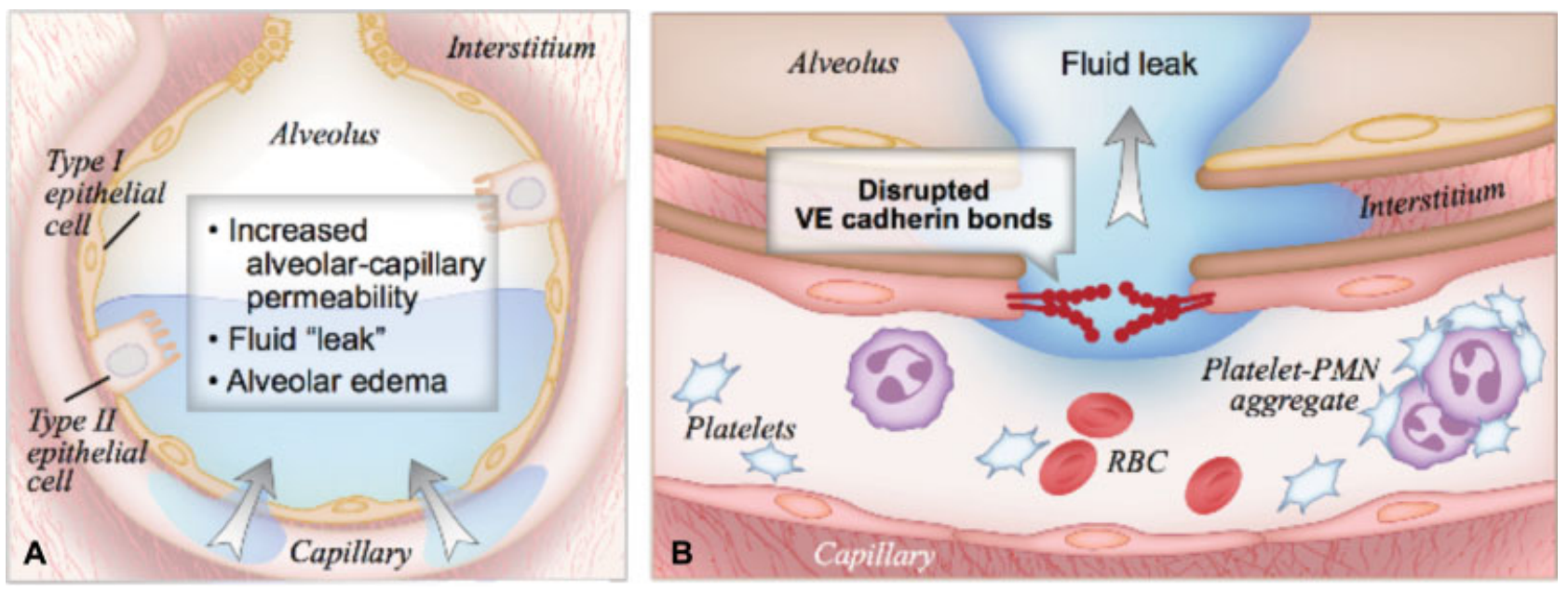

Fig. 1 Increased alveolar endothelial permeability in ARDS. (A) In ARDS, inflammatory molecules disrupt alveolar barrier function, resulting in the accumulation of alveolar edema fluid. (B) Specifically, disruption of VE-cadherin bonds causes increased endothelial permeability, and subsequent leakage of water, solutes, leukocytes, platelets, and other inflammatory molecules into the alveolar space. ARDS, acute respiratory distress syndrome; VE-cadherin, vascular endothelial cadherin. 
in increased epithelial permeability. ${ }^{17}$ Restitution of epithelial integrity is critical for recovery and survival in acute lung injury. Neutrophil transmigration triggers repair of the lung epithelium via $\beta$-catenin signaling, ${ }^{18}$ offering a potential therapeutic target to accelerate epithelial repair.

Finally, it is also important to note that environmental and genetic factors contribute to the susceptibility and severity of ARDS. Exposure to ambient air pollutants has been linked to risk of ARDS; this association is strongest in patients at risk for ARDS due to severe traumatic injuries. ${ }^{19,20}$ Active and passive cigarette smoke exposures have been associated with the development of ARDS after blunt force trauma, ${ }^{21}$ lung transplantation, ${ }^{22}$ and nonpulmonary sepsis. ${ }^{23}$ Chronic alcohol use increases the risk of acute lung injury. ${ }^{24}$ Genetic variants have also been identified that confer increased risk of developing ARDS and are predictive of disease severity. ${ }^{25}$ For example, genes involved in the inflammatory response and endothelial cell function, such as PPFIA1 and ANGPT2, were identified as candidate genes for ARDS risk following major trauma. ${ }^{26,27}$ Genetic variants in the FAS pathway, which regulates apoptosis and endothelial cell injury, were also associated with increased risk of ARDS. ${ }^{28}$ In African Americans, a candidate gene study identified that a T-46C polymorphism in the promoter region of the Duffy antigen/ receptor for chemokines $(D A R C)$ gene was associated with higher mortality. ${ }^{29}$ Additional studies are needed to better understand these environmental and genetic associations, which may further contribute to our understanding of the molecular pathways involved in ARDS pathogenesis.

\section{Slow Resolution: Alveolar Fluid Clearance Is Impaired in ARDS}

Pulmonary edema can develop from increased pulmonary vascular pressure from left heart failure (cardiogenic pulmonary edema $)^{30}$ or due to lung parenchymal damage from increased endothelial and epithelial permeabilities (noncardiogenic pulmonary edema, as in ARDS, as described earlier). ${ }^{31}$ In both cases, the mechanism for the resolution of alveolar edema is the same: active ion transport across the alveolar epithelium creates an osmotic gradient that drives AFC. ${ }^{7}$

Before discussing AFC in ARDS, it is important to review how alveolar fluid is normally cleared in the uninjured lung. In the uninjured lung, vectorial ion transport across the intact alveolar epithelial layer creates an osmotic gradient that drives fluid from the alveoli into the lung interstitium (-Fig. 2A). After fluid is cleared into the interstitium, it can be drained by lymphatics or reabsorbed into the vasculature based on the balance of forces described in Starling equation. It was initially thought that only alveolar epithelial type II cells were involved in vectorial ion transport, but subsequent studies demonstrated an important role for alveolar epithelial type I cells as well. ${ }^{32}$ The transport of sodium ions is the most important driver for the generation of the osmotic
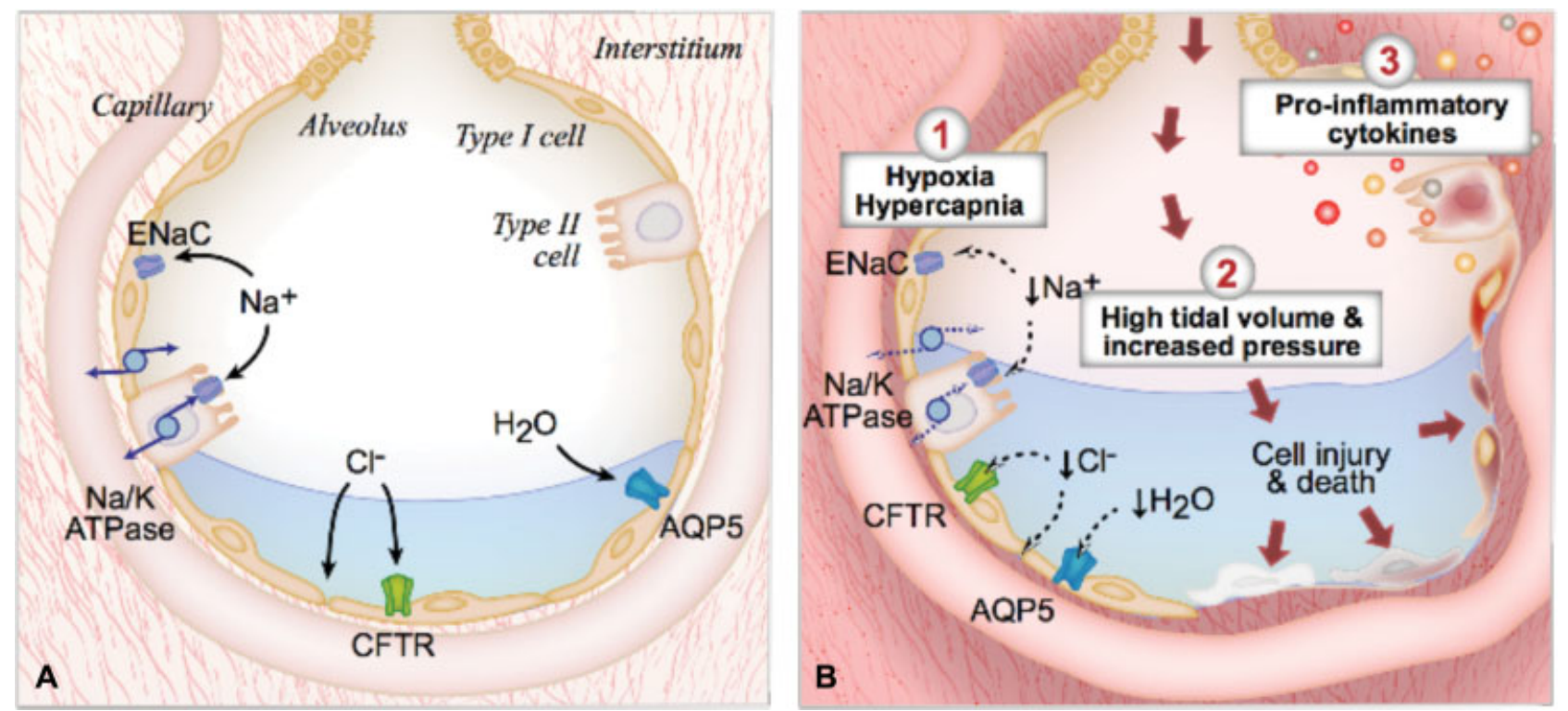

Fig. 2 Alveolar fluid clearance pathways in the uninjured lung versus the lung affected by ARDS. (A) In the uninjured lung, fluid is effectively cleared from the alveolar space by vectorial ion transport. Shown are the interstitial, capillary, and alveolar compartments of the lung, with pulmonary edema fluid in the alveolus. Both type I and type II alveolar cells are involved in transepithelial ion transport. Sodium ( $\mathrm{Na}^{+}$) is transported across the apical side of the type I and type II cells through the ENaC, and then across the basolateral side via the sodium/potassium ATPase pump ( $\mathrm{Na} / \mathrm{K}$-ATPase). Chloride $\left(\mathrm{Cl}^{-}\right)$is transported via the CFTR channel or by a paracellular route. Additional cation channels also transport ions across the alveolar epithelium (not shown). This vectorial ion transport creates an osmotic gradient that drives the clearance of fluid. Specifically, water $\left(\mathrm{H}_{2} \mathrm{O}\right)$ moves down the osmotic gradient through aquaporin channels, such as AQP5 or via an intracellular route (not shown). In the uninjured lung, this vectorial ion transport helps achieve effective alveolar fluid clearance. (B) In lungs affected by ARDS, fluid is less effectively cleared from the lungs. First, hypoxia/hypercapnia results in downregulation of ENaC transcription and trafficking and less efficient function of the Na/K-ATPase. Second, high tidal volumes and elevated airway pressures injure the alveolar epithelium, inducing inflammation and cell death. Third, ARDS results in the formation of proinflammatory cytokines, which induce alveolar injury and cause reduced alveolar fluid clearance. ARDS, acute respiratory distress syndrome; AQP5, aquaporin 5; CFTR, cystic fibrosis transmembrane conductance regulator; ENaC, epithelial sodium channel. 
gradient: sodium is transported through the epithelial sodium channel $(\mathrm{ENaC})$ on the apical surface, driven by the $\mathrm{Na} / \mathrm{K}$ ATPase on the basolateral surface. ${ }^{33,34}$ In animal models, this pathway is essential for survival; knockout of the $\alpha$ subunit of $\mathrm{ENaC}$ in mice results in the inability to remove alveolar fluid at birth, causing respiratory failure and premature death. ${ }^{35}$ In addition to $\mathrm{ENaC}$, nonselective cation channels, cyclic nucleotide-gated channels, and the cystic fibrosis transmembrane conductance regulator chloride channels also help maintain the osmotic gradient. ${ }^{36}$ Once the vectorial ion gradient is established, aquaporins facilitate the movement of water across the epithelial surface, but are not required for fluid transport. ${ }^{37}$ This system of active iondriven alveolar fluid reabsorption is the primary mechanism that removes alveolar edema fluid under both physiologic and pathological conditions. ${ }^{38,39}$ However, in the setting of ARDS, the capacity to remove alveolar edema fluid is reduced, which is termed impaired AFC. Patients with ARDS who have impaired AFC have decreased survival. ${ }^{40,41}$

There are multiple physiologic and molecular mechanisms that cause a reduction in AFC in ARDS (-Fig. 2B). First, the primary physiologic respiratory impairments that characterize ARDS, hypoxia and hypercapnia, can directly impair AFC. $\mathrm{ENaC}$ transcription and trafficking are downregulated and the $\mathrm{Na} / \mathrm{K}$-ATPase functions less efficiently under states of low oxygen or high carbon dioxide, in part because reactive oxygen species trigger endocytosis and cell necrosis. ${ }^{42-44}$ Therefore, supplemental oxygen and correction of hypercapnia can enhance the resolution of alveolar edema by helping to maintain active sodium transport across the lung epithelium.

Second, biomechanical stress in the lung can reduce AFC. High tidal volumes and elevated airway pressures injure the alveolar epithelium, inducing cell death and inflammation, which further reduces AFC. ${ }^{45}$ If pulmonary hydrostatic pressures are elevated, the rate of net AFC is also reduced. These findings help explain the success of lung protective ventilation and conservative fluid strategies in reducing the morbidity and mortality of ARDS. ${ }^{46,47}$

Third, we now better understand the molecular mechanisms that contribute to the reduction in AFC in ARDS. Specifically, ARDS pulmonary edema fluid contains high levels of proinflammatory cytokines including interleukin (IL)-1 $\beta$, IL-8, TNF- $\alpha$, and transforming growth factor- $\beta 1 .{ }^{48-50}$ When excessive levels of cytokines are present, they cause alveolar injury and reduced AFC. ${ }^{51-54}$ This was elegantly demonstrated in an in vitro model of polarized human type II alveolar cells in 2006. Specifically, the authors showed that there are increased levels of cytokines and decreased levels of ion transport proteins in the presence of ARDS edema fluid compared with a plasma control. ${ }^{55,56}$ Specifically, it is thought that the inflammatory edema fluid causes alveolar cell injury and necrosis, negating the tight epithelial barrier needed to establish an osmotic gradient and offsetting the effects of vectorial ion transport. ${ }^{57,58}$ Cell necrosis and fluid accumulation in turn can trigger an even more pronounced inflammatory and immune response. ${ }^{59}$ There are no current therapies that directly modify AFC, although lung protective ventilation itself reduces proinflammatory cytokines such as IL-6 and IL-8. ${ }^{60}$
Ultimately, resolution of ARDS requires repair of the endothelial and epithelial barriers to allow for effective reabsorption of the alveolar edema fluid, as well as removal of inflammatory cells and cytokines from the airspaces and the lung interstitium. To repair the alveolar epithelial barrier, type II cells must proliferate and differentiate. ${ }^{61}$ Progenitor cells are present in the bronchoalveolar junctions that aid in the regeneration of the endothelial and epithelial barrier, ${ }^{62}$ and macrophages also contribute to tissue repair. ${ }^{63}$ With repair of the endothelial and epithelial barrier, reabsorption of alveolar edema fluid can occur more efficiently via vectorial transport.

In addition to repairing the microvascular barrier, the resolution of ARDS requires clearance of neutrophils, monocytes, and anti-inflammatory molecules by macrophages ${ }^{64,65}$ and lymphocytes. ${ }^{66}$ In a mouse model of influenza pneumonia, depletion of alveolar macrophages lead to an increased number of neutrophils and neutrophil extracellular traps, as well as slower recovery from lung injury. ${ }^{67}$ Similarly, in a mouse model of endotoxin-induced lung injury, CD4 + CD25+ regulatory T cells suppressed cytokine secretion and enhanced neutrophil apoptosis, aiding in faster resolution of lung injury. ${ }^{66}$

\section{Clinical Trials and Novel Therapeutics Offer Further Insight about ARDS Pathogenesis}

Since the first description of ARDS 50 years ago, there have been numerous clinical trials evaluating the efficacy of physiologic and pharmacologic interventions. Not only have these trials defined clinical practices but they also have enhanced our understanding of the pathophysiology of this condition.

Multiple clinical trials have supported the use of lung protective ventilation, with lower tidal volumes and airway pressures, to reduce morality in ARDS. ${ }^{46,68-70}$ Follow-up studies investigated why this strategy is effective. In a rat model of ARDS, resolution of alveolar edema was threefold faster with a tidal volume of $6 \mathrm{mg} / \mathrm{kg}$ as opposed to $12 \mathrm{mg} / \mathrm{kg}$, in part due to decreased lung epithelial injury. ${ }^{44}$ Similarly in human studies, patients who were subjected to lung protective ventilation had reduced markers of lung epithelial injury $^{71}$ and reduced proinflammatory molecules (neutrophils, IL-6, IL-8, and soluble TNF receptor 1$).{ }^{60,72}$

Another central concept in ARDS treatment is the utilization of a conservative fluid management strategy, which was first suggested to be effective in the late $1970 \mathrm{~s}^{73}$ and was later confirmed by a large ARDS Network Trial. ${ }^{74}$ The beneficial effect of a conservative fluid strategy is thought to be due to the fact that lowering vascular pressures reduces transvascular fluid filtration across the injured alveolar capillary barrier. There is also evidence that a conservative fluid strategy results in decreased plasma levels of angiopoietin-2, suggesting that this strategy also has a protective effect on the vascular endothelium. ${ }^{75}$ Further studies are needed to better understand the molecular mechanisms underlying this process.

Given that ARDS is a proinflammatory state, there have also been numerous clinical trials evaluating anti-inflammatory agents as a potential treatment for ARDS. However, clinical trials of glucocorticoids, ${ }^{76-78}$ granulocyte macrophage colony- 
stimulating factor, ${ }^{79}$ and antioxidants ${ }^{80}$ have not shown clinical utility to date. Similarly, it was hypothesized that anticoagulant therapy may be effective in ARDS treatment given the known interplay between procoagulant and proinflammatory pathways. However, a trial testing activated protein $C$ did not reduce mortality in patients with nonseptic ARDS. ${ }^{81}$ While none of these trials suggests clinical benefit in ARDS treatment, it is possible that these therapies only improve outcomes in certain subphenotypes of ARDS. There is significant clinical and biological heterogeneity in ARDS, and recent studies suggest that there are two distinct and consistent subphenotypes of this condition. ${ }^{82,83}$ Approximately $30 \%$ of patients have a hyperinflammatory subphenotype, which is characterized by increased inflammatory markers, more severe acidosis and shock, and worse clinical outcomes. Future clinical trials should consider these subphenotypes, as they may help us better understand ARDS pathophysiology and also may respond differentially to therapeutic interventions. For example, a large randomized controlled clinical trial of simvastatin therapy in ARDS showed no mortality difference in the treatment versus placebo groups, ${ }^{84}$ but secondary analysis showed decreased mortality in the patients with the hyperinflammatory subphenotype of ARDS, ${ }^{85}$ suggesting some role for anti-inflammatory treatments in this subphenotype.

Another therapeutic strategy that has been proposed is to target molecules that stabilize endothelial and epithelial cell-cell junctions, given the central role of alveolar endothelial and epithelial permeabilities in ARDS pathogenesis. Sphingosine 1-phosphate (S1P) is a lipid that is recognized by $G$ protein-coupled receptors on endothelial cells (e.g., S1Pr1) and mediates endothelial barrier integrity. ${ }^{86}$ In both in vitro and in vivo models, S1P enhances pulmonary and systemic endothelial integrity, ${ }^{87}$ and small-molecule agonists of endothelial S1Pr1 decrease cytokine and leukocyte recruitment in mouse models of influenza infection. ${ }^{88}$ Specifically, S1P binds to S1Pr1 which induces actin cytoskeleton reorganization and localization of catenin and VE-cadherin molecules to the endothelial surface. ${ }^{89}$ The Robo4/Slit signaling system also stabilizes the endothelial barrier. Slit2N inhibits tyrosine phosphorylation of VE-cadherin, preventing the internalization of VE-cadherin and the resultant increased endothelial permeability triggered by TNF- $\alpha$, IL1, or LPS. ${ }^{90}$ Studying proteins that help stabilize the endothelial and epithelial barriers has therapeutic potential, and also may offer further insight into the mechanisms that underlie endothelial and epithelial permeabilities.

Aside from targeting specific proteins that have therapeutic potential, most recently, mesenchymal stromal cells (MSCs) have been recognized as a promising new cell-based therapy for ARDS, further informing our understanding of ARDS pathogenesis. MSCs are bone marrow-derived cells that can differentiate in vitro into chondrocytes, osteoblasts, and adipocytes, although they do not have true stem cell properties in vivo. ${ }^{91}$ The therapeutic potential of MSCs has been studied in several medical and surgical conditions including sepsis, ${ }^{92,93}$ diabetes, ${ }^{94}$ myocardial infarction, ${ }^{95}$ hepatic failure, ${ }^{96}$ acute renal failure, ${ }^{97,98}$ chronic obstructive pulmonary disease, ${ }^{99}$ neurologic injuries, ${ }^{100}$ graft-versus- host disease, ${ }^{101}$ and trauma. ${ }^{102}$ Therefore, it was hypothesized that MSCs may also be beneficial in the treatment of ARDS. To test this hypothesis, several groups studied whether MSCs reduce the severity of lung injury in preclinical models. Treatment with MSCs improved survival and reduced pulmonary edema in Escherichia coli endotoxininduced lung injury in mice. ${ }^{103}$ Subsequent studies showed that MSCs attenuated lung injury caused by live bacteria in mouse, rat, and in ex vivo human lung models of lung injury. ${ }^{104-106}$ In addition, MSCs enhanced bacterial clearance and improved survival in murine models of sepsis. ${ }^{93,107}$

Given the potential therapeutic benefit of MSCs in the treatment of ARDS, many groups have sought to understand their mechanism of action, and several possible mechanisms have been proposed to date (-Fig. 3). Initially, it was thought that MSCs engrafted at the site of tissue injury and provided direct structural benefit. ${ }^{108}$ However, with more detailed cell identification methods, engraftment is now thought to be a rare event of unclear physiologic significance. ${ }^{109}$ Instead, the beneficial effect of MSCs does not require direct cell contact and several paracrine mechanisms have been proposed. First, it has been suggested that MSCs secrete proteins that have anti-inflammatory properties, and several have been identified to date: IL-1 receptor antagonist (IL1-ra), ${ }^{110}$ TNF- $\alpha$ stimulated gene six (TSG-6), ${ }^{111}$ insulin-like growth factor $1,{ }^{112}$ and lipoxin A4. ${ }^{113}$ of note, clinical trials studying systemic

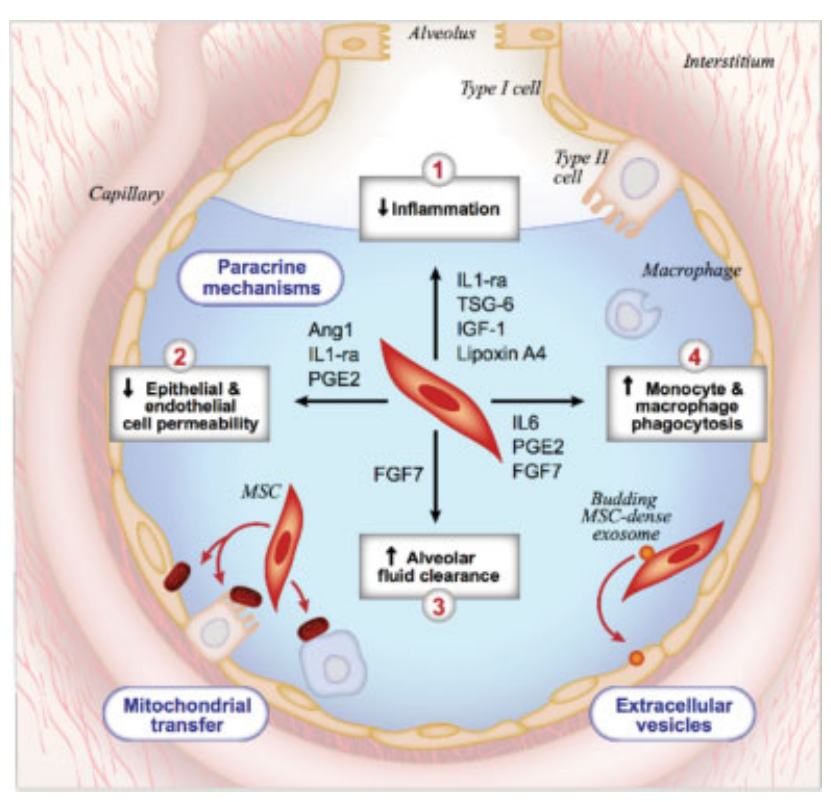

Fig. 3 Potential mechanisms for the therapeutic effects of MSCs in ARDS. To date, multiple preclinical studies have demonstrated the therapeutic benefit of MSCs in the treatment of ARDS, and this diagram depicts our current mechanistic understanding of this therapeutic effect. First, MSCs secrete paracrine factors that modulate tissue repair through four mechanisms: (1) anti-inflammatory effects on host cells, (2) reduction of alveolar epithelial permeability in the lung, (3) increased rate of alveolar fluid clearance, and (4) enhancement of host mononuclear cell phagocytic activity. Second, data suggest that MSCs directly transfer mitochondrial DNA to host cells, which also contributes to tissue repair and recovery. Third, MSCs secrete microvesicles that deliver micro RNA, RNA, proteins, and lipids to host cells. ARDS, acute respiratory distress syndrome; MSCs, mesenchymal stromal cells 
anti-inflammatory agents have not been beneficial as previously described, but MSC therapy may provide anti-inflammatory effects that are multimodal and responsive to the cellular microenvironment in the lung. Second, there is evidence to suggest that MSCs affect lung endothelial and alveolar epithelial permeabilities via a paracrine mechanism, and the proteins angiopoietin-1, IL1-ra, and prostaglandin E2 have been implicated in this process. ${ }^{114,115}$ Third, MSCs may secrete paracrine factors that improve AFC, with evidence to suggest that fibroblast growth factor 7 may be particularly important in this process. ${ }^{116,117}$ Fourth, apoptosis of both immune and structural cells occurs during ARDS, so it has been suggested that paracrine factors such as IL- $6^{118}$ and keratinocyte growth factor ${ }^{106}$ may have beneficial antiapoptotic effects. Finally, MSCs have the capacity to alter the polarization of alveolar macrophages to an M2-like proresolving phenotype. ${ }^{119}$

While numerous studies suggest that paracrine factors are responsible for the beneficial effects of MSCs, more recent studies propose alternative mechanisms of action. For example, there is some evidence to suggest that MSCs mediate tissue repair through direct transfer of mitochondrial DNA to host cells. ${ }^{120-122}$ Alternatively, it has been proposed that there are extracellular vesicles that bud off of MSCs and transfer biologically active material to host cells that have beneficial effects. $^{123,124}$ Thus, there may be several mechanisms by which MSCs mediate the resolution of lung injury, and further studies are needed to clarify key mechanisms of action.

Based on these preclinical data, phases 1 and 2 clinical trials are currently testing whether MSCs have therapeutic potential in humans. ${ }^{125}$ Most recently, a prospective, doubleblind, multicenter, phase 2a randomized controlled trial demonstrated that it is safe to administer a single intravenous dose of MSCs in patients with moderate-severe ARDS, ${ }^{126}$ so larger trials are needed to assess efficacy. Of note, the authors noted varying viability of the MSCs in this study, so it will be important to improve protocols to improve MSC viability in the future.

\section{Conclusion}

Over the past 50 years, there have been substantial advances in our understanding of ARDS pathogenesis. In vitro and in vivo studies have demonstrated that lung inflammation causes increased alveolar endothelial and epithelial permeabilities, resulting in the accumulation of pulmonary edema fluid. In ARDS, the mechanisms that typically remove pulmonary edema fluid are less effective. The study of novel therapeutic strategies, including cell-based MSC treatment, has further refined our understanding of ARDS pathophysiology, and may offer promising new treatment options for this condition. In addition, new therapies may be more effective if targeted to specific subphenotypes of ARDS defined by clinical and biological factors.

\section{Conflict of Interest}

This work was conducted in the absence of any commercial or financial relationships that could be construed as a potential conflict of interest.

\section{Acknowledgments}

The authors thank Diana Lim for creating the figures for this article. Dr. Matthay was supported in part by NHLBI HL51856 and NHLBI HL108713. Dr. Ware was supported in part by NIH HL103836.

\section{References}

1 Matthay MA, Ware LB, Zimmerman GA. The acute respiratory distress syndrome. J Clin Invest 2012;122(08):2731-2740

2 Ferguson ND, Fan E, Camporota L, et al. The Berlin definition of ARDS: an expanded rationale, justification, and supplementary material. Intensive Care Med 2012;38(10):1573-1582

3 Villar J, Blanco J, Kacmarek RM. Current incidence and outcome of the acute respiratory distress syndrome. Curr Opin Crit Care 2016;22(01):1-6

4 Rubenfeld GD, Caldwell E, Peabody E, et al. Incidence and outcomes of acute lung injury. N Engl J Med 2005;353(16): 1685-1693

5 Máca J, Jor O, Holub M, et al. Past and present ARDS mortality rates: a systematic review. Respir Care 2017;62(01):113-122

6 Ashbaugh DG, Bigelow DB, Petty TL, Levine BE. Acute respiratory distress in adults. Lancet 1967;2(7511):319-323

7 Matthay MA, Folkesson HG, Clerici C. Lung epithelial fluid transport and the resolution of pulmonary edema. Physiol Rev 2002;82(03):569-600

8 Opitz B, van Laak V, Eitel J, Suttorp N. Innate immune recognition in infectious and noninfectious diseases of the lung. Am J Respir Crit Care Med 2010;181(12):1294-1309

9 Mantovani A, Cassatella MA, Costantini C, Jaillon S. Neutrophils in the activation and regulation of innate and adaptive immunity. Nat Rev Immunol 2011;11(08):519-531

10 Imai Y, Kuba K, Neely GG, et al. Identification of oxidative stress and Toll-like receptor 4 signaling as a key pathway of acute lung injury. Cell 2008;133(02):235-249

11 Vestweber D. VE-cadherin: the major endothelial adhesion molecule controlling cellular junctions and blood vessel formation. Arterioscler Thromb Vasc Biol 2008;28(02):223-232

12 Corada M, Mariotti M, Thurston G, et al. Vascular endothelialcadherin is an important determinant of microvascular integrity in vivo. Proc Natl Acad Sci U S A 1999;96(17):9815-9820

13 Schulte D, Küppers V, Dartsch N, et al. Stabilizing the VEcadherin-catenin complex blocks leukocyte extravasation and vascular permeability. EMBO J 2011;30(20):4157-4170

14 Broermann A, Winderlich M, Block H, et al. Dissociation of VEPTP from VE-cadherin is required for leukocyte extravasation and for VEGF-induced vascular permeability in vivo. J Exp Med 2011;208(12):2393-2401

15 Zemans RL, Matthay MA. Bench-to-bedside review: the role of the alveolar epithelium in the resolution of pulmonary edema in acute lung injury. Crit Care 2004;8(06):469-477

16 Wiener-Kronish JP, Albertine KH, Matthay MA. Differential responses of the endothelial and epithelial barriers of the lung in sheep to Escherichia coli endotoxin. J Clin Invest 1991;88(03): 864-875

17 Ginzberg HH, Shannon PT, Suzuki T, et al. Leukocyte elastase induces epithelial apoptosis: role of mitochondrial permeability changes and Akt. Am J Physiol Gastrointest Liver Physiol 2004; 287(01):G286-G298

18 Zemans RL, Briones N, Campbell M, et al. Neutrophil transmigration triggers repair of the lung epithelium via $\beta$-catenin signaling. . Proceedings of the National Academy of Sciences 2011:201110144

19 Ware LB, Zhao Z, Koyama T, et al. Long-term ozone exposure increases the risk of developing the acute respiratory distress syndrome. Am J Respir Crit Care Med 2016;193(10):1143-1150 
20 Reilly JP, Zhao Z, Shashaty MGS, et al. Low to moderate air pollutant exposure and acute respiratory distress syndrome after severe trauma. Am J Respir Crit Care Med 2019;199(01):62-70

21 Calfee CS, Matthay MA, Eisner MD, et al. Active and passive cigarette smoking and acute lung injury after severe blunt trauma. Am J Respir Crit Care Med 2011;183(12):1660-1665

22 Diamond JM, Lee JC, Kawut SM, et al; Lung Transplant Outcomes Group. Clinical risk factors for primary graft dysfunction after lung transplantation. Am J Respir Crit Care Med 2013;187(05): 527-534

23 Calfee CS, Matthay MA, Kangelaris KN, et al. Cigarette smoke exposure and the acute respiratory distress syndrome. Crit Care Med 2015;43(09):1790-1797

24 Moss M, Burnham EL. Chronic alcohol abuse, acute respiratory distress syndrome, and multiple organ dysfunction. Crit Care Med 2003;31(4, Suppl):S207-S212

25 Gao L, Barnes KC. Recent advances in genetic predisposition to clinical acute lung injury. Am J Physiol Lung Cell Mol Physiol 2009;296(05):L713-L725

26 Christie JD, Wurfel MM, Feng R, et al; Trauma ALI SNP Consortium (TASC) investigators. Genome wide association identifies PPFIA1 as a candidate gene for acute lung injury risk following major trauma. PLoS One 2012;7(01):e28268

27 Meyer NJ, Li M, Feng R, et al. ANGPT2 genetic variant is associated with trauma-associated acute lung injury and altered plasma angiopoietin-2 isoform ratio. Am J Respir Crit Care Med 2011; 183(10):1344-1353

28 Glavan BJ, Holden TD, Goss CH, et al; ARDSnet Investigators. Genetic variation in the FAS gene and associations with acute lung injury. Am J Respir Crit Care Med 2011;183(03):356-363

29 Kangelaris KN, Sapru A, Calfee CS, et al; National Heart, Lung, and Blood Institute ARDS Network. The association between a Darc gene polymorphism and clinical outcomes in African American patients with acute lung injury. Chest 2012;141(05):1160-1169

30 Staub NC. The pathogenesis of pulmonary edema. Prog Cardiovasc Dis 1980;23(01):53-80

31 Staub NC. Pulmonary edema due to increased microvascular permeability. Annu Rev Med 1981;32:291-312

32 Johnson MD, Widdicombe JH, Allen L, Barbry P, Dobbs LG. Alveolar epithelial type I cells contain transport proteins and transport sodium, supporting an active role for type I cells in regulation of lung liquid homeostasis. Proc Natl Acad Sci U S A 2002;99(04):1966-1971

33 Canessa CM, Schild L, Buell G, et al. Amiloride-sensitive epithelial $\mathrm{Na}+$ channel is made of three homologous subunits. Nature 1994;367(6462):463-467

34 Matalon S, O'Brodovich H. Sodium channels in alveolar epithelial cells: molecular characterization, biophysical properties, and physiological significance. Annu Rev Physiol 1999;61:627-661

35 Hummler E, Barker P, Gatzy J, et al. Early death due to defective neonatal lung liquid clearance in $\alpha$-ENaC-deficient mice. Nat Genet 1996;12(03):325-328

36 Fang X, Fukuda N, Barbry P, Sartori C, Verkman AS, Matthay MA. Novel role for CFTR in fluid absorption from the distal airspaces of the lung. J Gen Physiol 2002;119(02):199-207

37 Verkman AS, Matthay MA, Song Y. Aquaporin water channels and lung physiology. Am J Physiol Lung Cell Mol Physiol 2000;278 (05):L867-L879

38 Eaton DC, Chen J, Ramosevac S, Matalon S, Jain L. Regulation of $\mathrm{Na}+$ channels in lung alveolar type II epithelial cells. Proc Am Thorac Soc 2004; 1(01):10-16

39 Mutlu GM, Sznajder JI. Mechanisms of pulmonary edema clearance. Am J Physiol Lung Cell Mol Physiol 2005;289(05):L685-L695

40 Matthay MA, Wiener-Kronish JP. Intact epithelial barrier function is critical for the resolution of alveolar edema in humans. Am Rev Respir Dis 1990;142(6 Pt 1):1250-1257

41 Ware LB, Matthay MA. Alveolar fluid clearance is impaired in the majority of patients with acute lung injury and the acute respiratory distress syndrome. Am J Respir Crit Care Med 2001;163(06):1376-1383

42 Vivona ML, Matthay M, Chabaud MB, Friedlander G, Clerici C. Hypoxia reduces alveolar epithelial sodium and fluid transport in rats: reversal by $\beta$-adrenergic agonist treatment. Am J Respir Cell Mol Biol 2001;25(05):554-561

43 Vadász I, Raviv S, Sznajder JI. Alveolar epithelium and Na,KATPase in acute lung injury. Intensive Care Med 2007;33(07): 1243-1251

44 Briva A, Vadász I, Lecuona E, et al. High CO2 levels impair alveolar epithelial function independently of pH. PLoS One 2007;2(11): e1238

45 Frank JA, Gutierrez JA, Jones KD, Allen L, Dobbs L, Matthay MA. Low tidal volume reduces epithelial and endothelial injury in acid-injured rat lungs. Am J Respir Crit Care Med 2002;165(02): 242-249

46 Brower RG, Matthay MA, Morris A, Schoenfeld D, Thompson BT, Wheeler A; Acute Respiratory Distress Syndrome Network. Ventilation with lower tidal volumes as compared with traditional tidal volumes for acute lung injury and the acute respiratory distress syndrome. N Engl J Med 2000;342(18):1301-1308

47 Schuller D, Schuster DP. Fluid-management strategies in acute lung injury. N Engl J Med 2006;355(11):1175, author reply 1176

48 Pugin J, Verghese G, Widmer MC, Matthay MA. The alveolar space is the site of intense inflammatory and profibrotic reactions in the early phase of acute respiratory distress syndrome. Crit Care Med 1999;27(02):304-312

49 Olman MA, White KE, Ware LB, et al. Pulmonary edema fluid from patients with early lung injury stimulates fibroblast proliferation through IL-1 $\beta$-induced IL-6 expression. J Immunol 2004;172(04):2668-2677

50 Ware LB, Matthay MA. The acute respiratory distress syndrome. N Engl J Med 2000;342(18):1334-1349

51 Fukuda N, Jayr C, Lazrak A, et al. Mechanisms of TNF- $\alpha$ stimulation of amiloride-sensitive sodium transport across alveolar epithelium. Am J Physiol Lung Cell Mol Physiol 2001;280(06): L1258-L1265

52 Elia N, Tapponnier M, Matthay MA, et al. Functional identification of the alveolar edema reabsorption activity of murine tumor necrosis factor- $\alpha$. Am J Respir Crit Care Med 2003;168(09): 1043-1050

53 Dagenais A, Fréchette R, Yamagata Y, et al. Downregulation of ENaC activity and expression by TNF- $\alpha$ in alveolar epithelial cells. Am J Physiol Lung Cell Mol Physiol 2004;286(02):L301-L311

54 Roux J, Kawakatsu H, Gartland B, et al. Interleukin-1 $\beta$ decreases expression of the epithelial sodium channel $\alpha$-subunit in alveolar epithelial cells via a p38 MAPK-dependent signaling pathway. J Biol Chem 2005;280(19):18579-18589

55 Fang X, Song Y, Hirsch J, et al. Contribution of CFTR to apicalbasolateral fluid transport in cultured human alveolar epithelial type II cells. Am J Physiol Lung Cell Mol Physiol 2006;290(02): L242-L249

56 Lee JW, Fang X, Dolganov G, et al. Acute lung injury edema fluid decreases net fluid transport across human alveolar epithelial type II cells. J Biol Chem 2007;282(33):24109-24119

57 Zemans RL, Colgan SP, Downey GP. Transepithelial migration of neutrophils: mechanisms and implications for acute lung injury. Am J Respir Cell Mol Biol 2009;40(05):519-535

58 Calfee CS, Matthay MA. Clinical immunology: culprits with evolutionary ties. Nature 2010;464(7285):41-42

59 Hung CF, Mittelsteadt KL, Brauer R, et al. Lung pericyte-like cells are functional interstitial immune sentinel cells. Am J Physiol Lung Cell Mol Physiol 2017;312(04):L556-L567

60 Parsons PE, Eisner MD, Thompson BT, et al; NHLBI Acute Respiratory Distress Syndrome Clinical Trials Network. Lower tidal volume ventilation and plasma cytokine markers of inflammation in patients with acute lung injury. Crit Care Med 2005;33 (01):1-6, discussion 230-232 
61 Adamson IY, Bowden DH. The type 2 cell as progenitor of alveolar epithelial regeneration. A cytodynamic study in mice after exposure to oxygen. Lab Invest 1974;30(01):35-42

$62 \mathrm{Kim}$ CF, Jackson EL, Woolfenden AE, et al. Identification of bronchioalveolar stem cells in normal lung and lung cancer. Cell 2005;121(06):823-835

63 Aggarwal NR, King LS, D’Alessio FR. Diverse macrophage populations mediate acute lung inflammation and resolution. Am J Physiol Lung Cell Mol Physiol 2014;306(08):L709-L725

64 Serhan CN, Brain SD, Buckley CD, et al. Resolution of inflammation: state of the art, definitions and terms. FASEB J 2007;21(02): 325-332

65 Bratton DL, Henson PM. Neutrophil clearance: when the party is over, clean-up begins. Trends Immunol 2011;32(08):350-357

66 D'Alessio FR, Tsushima K, Aggarwal NR, et al. CD4+CD25+Foxp3+ Tregs resolve experimental lung injury in mice and are present in humans with acute lung injury. J Clin Invest 2009;119(10):2898-2913

67 Narasaraju T, Yang E, Samy RP, et al. Excessive neutrophils and neutrophil extracellular traps contribute to acute lung injury of influenza pneumonitis. Am J Pathol 2011;179(01):199-210

68 Amato MB, Barbas CS, Medeiros DM, et al. Effect of a protectiveventilation strategy on mortality in the acute respiratory distress syndrome. N Engl J Med 1998;338(06):347-354

69 Eichacker PQ, Gerstenberger EP, Banks SM, Cui X, Natanson C. Meta-analysis of acute lung injury and acute respiratory distress syndrome trials testing low tidal volumes. Am J Respir Crit Care Med 2002;166(11):1510-1514

70 Villar J, Kacmarek RM, Pérez-Méndez L, Aguirre-Jaime A. A high positive end-expiratory pressure, low tidal volume ventilatory strategy improves outcome in persistent acute respiratory distress syndrome: a randomized, controlled trial. Crit Care Med 2006;34(05):1311-1318

71 Calfee CS, Ware LB, Eisner MD, et al; NHLBI ARDS Network. Plasma receptor for advanced glycation end products and clinical outcomes in acute lung injury. Thorax 2008;63(12):1083-1089

72 Ranieri VM, Suter PM, Tortorella C, et al. Effect of mechanical ventilation on inflammatory mediators in patients with acute respiratory distress syndrome: a randomized controlled trial. JAMA 1999;282(01):54-61

73 Staub NC. Pulmonary edema: physiologic approaches to management. Chest 1978;74(05):559-564

74 National Heart, Lung, and Blood Institute Acute Respiratory Distress Syndrome (ARDS) Clinical Trials Network. Comparison of two fluid-management strategies in acute lung injury. $\mathrm{N}$ Engl J Med 2006;354:2564-2575

75 Calfee CS, Gallagher D, Abbott J, Thompson BT, Matthay MA; NHLBI ARDS Network. Plasma angiopoietin-2 in clinical acute lung injury: prognostic and pathogenetic significance. Crit Care Med 2012;40(06):1731-1737

76 Bernard GR, Luce JM, Sprung CL, et al. High-dose corticosteroids in patients with the adult respiratory distress syndrome. $\mathrm{N}$ Engl J Med 1987;317(25):1565-1570

77 Meduri GU, Headley AS, Golden E, et al. Effect of prolonged methylprednisolone therapy in unresolving acute respiratory distress syndrome: a randomized controlled trial. JAMA 1998; 280(02):159-165

78 National Heart, Lung, and Blood Institute Acute Respiratory Distress Syndrome (ARDS) Clinical Trials Network. Efficacy and safety of corticosteroids for persistent acute respiratory distress syndrome. N Engl J Med 2006;354:1671-1684

79 Nemunaitis J, Rabinowe SN, Singer JW, et al. Recombinant granulocyte-macrophage colony-stimulating factor after autologous bone marrow transplantation for lymphoid cancer. N Engl J Med 1991;324(25):1773-1778

80 Bernard GR, Wheeler AP, Arons MM, et al; The Antioxidant in ARDS Study Group. A trial of antioxidants $\mathrm{N}$-acetylcysteine and procysteine in ARDS. Chest 1997;112(01):164-172
81 Liu KD, Levitt J, Zhuo H, et al. Randomized clinical trial of activated protein $C$ for the treatment of acute lung injury. Am J Respir Crit Care Med 2008;178(06):618-623

82 Calfee CS, Delucchi K, Parsons PE, Thompson BT, Ware LB, Matthay MA; NHLBI ARDS Network. Subphenotypes in acute respiratory distress syndrome: latent class analysis of data from two randomised controlled trials. Lancet Respir Med 2014;2 (08):611-620

83 Famous KR, Delucchi K, Ware LB, et al; ARDS Network. Acute respiratory distress syndrome subphenotypes respond differently to randomized fluid management strategy. Am J Respir Crit Care Med 2017;195(03):331-338

84 McAuley DF, Laffey JG, O'Kane CM, et al; HARP-2 Investigators; Irish Critical Care Trials Group. Simvastatin in the acute respiratory distress syndrome. N Engl J Med 2014;371(18):1695-1703

85 Calfee CS, Delucchi KL, Sinha P, et al; Irish Critical Care Trials Group. Acute respiratory distress syndrome subphenotypes and differential response to simvastatin: secondary analysis of a randomised controlled trial. Lancet Respir Med 2018;6(09):691-698

86 Lee MJ, Thangada S, Claffey KP, et al. Vascular endothelial cell adherens junction assembly and morphogenesis induced by sphingosine-1-phosphate. Cell 1999;99(03):301-312

87 Xiong Y, Hla T. S1P control of endothelial integrity. In: Sphingosine-1-Phosphate Signaling in Immunology and Infectious Diseases. Cham, Switzerland: Springer; 2014:85-105

88 Teijaro JR, Walsh KB, Cahalan S, et al. Endothelial cells are central orchestrators of cytokine amplification during influenza virus infection. Cell 2011;146(06):980-991

89 Obinata H, Hla T. Sphingosine 1-phosphate in coagulation and inflammation. Semin Immunopathol 2012;34(01):73-91

90 London NR, Zhu W, Bozza FA, et al. Targeting Robo4-dependent Slit signaling to survive the cytokine storm in sepsis and influenza. Sci Transl Med 2010;2(23):23ra19

91 Friedenstein AJ, Petrakova KV, Kurolesova AI, Frolova GP. Heterotopic of bone marrow. Analysis of precursor cells for osteogenic and hematopoietic tissues. Transplantation 1968;6(02):230-247

92 Németh K, Leelahavanichkul A, Yuen PS, et al. Bone marrow stromal cells attenuate sepsis via prostaglandin E(2)-dependent reprogramming of host macrophages to increase their interleukin-10 production. Nat Med 2009;15(01):42-49

93 Mei SH, Haitsma JJ, Dos Santos CC, et al. Mesenchymal stem cells reduce inflammation while enhancing bacterial clearance and improving survival in sepsis. Am J Respir Crit Care Med 2010;182 (08):1047-1057

94 Lee RH, Seo MJ, Reger RL, et al. Multipotent stromal cells from human marrow home to and promote repair of pancreatic islets and renal glomeruli in diabetic NOD/scid mice. Proc Natl Acad Sci U S A 2006;103(46):17438-17443

$95 \mathrm{Li} \mathrm{TS}$, Hayashi M, Ito H, et al. Regeneration of infarcted myocardium by intramyocardial implantation of ex vivo transforming growth factor- $\beta$-preprogrammed bone marrow stem cells. Circulation 2005;111(19):2438-2445

96 Parekkadan B, van Poll D, Suganuma K, et al. Mesenchymal stem cell-derived molecules reverse fulminant hepatic failure. PLoS One 2007;2(09):e941

97 Tögel F, Hu Z, Weiss K, Isaac J, Lange C, Westenfelder C. Administered mesenchymal stem cells protect against ischemic acute renal failure through differentiation-independent mechanisms. Am J Physiol Renal Physiol 2005;289(01):F31-F42

98 Ullah I, Subbarao RB, Rho GJ. Human mesenchymal stem cells current trends and future prospective. Biosci Rep 2015;35(02): e00191

99 Weiss DJ, Cruz FF. A placebo-controlled, randomized trial of mesenchymal stromal cells combined with one-way endobronchial valve therapy in severe COPD. Cytotherapy 2016;18:S17

$100 \mathrm{Hu}$ SL, Luo HS, Li JT, et al. Functional recovery in acute traumatic spinal cord injury after transplantation of human umbilical cord mesenchymal stem cells. Crit Care Med 2010;38(11):2181-2189 
101 Le Blanc K, Frassoni F, Ball L, et al; Developmental Committee of the European Group for Blood and Marrow Transplantation. Mesenchymal stem cells for treatment of steroid-resistant, severe, acute graft-versus-host disease: a phase II study. Lancet 2008;371(9624):1579-1586

102 Matthay MA, Pati S, Lee JW. Concise review: mesenchymal stem (stromal) cells: biology and preclinical evidence for therapeutic potential for organ dysfunction following trauma or sepsis. Stem Cells 2017;35(02):316-324

103 Gupta N, Su X, Popov B, Lee JW, Serikov V, Matthay MA. Intrapulmonary delivery of bone marrow-derived mesenchymal stem cells improves survival and attenuates endotoxin-induced acute lung injury in mice. J Immunol 2007;179(03):1855-1863

104 Gupta N, Krasnodembskaya A, Kapetanaki M, et al. Mesenchymal stem cells enhance survival and bacterial clearance in murine Escherichia coli pneumonia. Thorax 2012;67(06):533-539

105 Devaney J, Horie S, Masterson C, et al. Human mesenchymal stromal cells decrease the severity of acute lung injury induced by $E$. coli in the rat. Thorax 2015;70(07):625-635

106 Lee JW, Krasnodembskaya A, McKenna DH, Song Y, Abbott J, Matthay MA. Therapeutic effects of human mesenchymal stem cells in ex vivo human lungs injured with live bacteria. Am J Respir Crit Care Med 2013;187(07):751-760

107 Walter J, Ware LB, Matthay MA. Mesenchymal stem cells: mechanisms of potential therapeutic benefit in ARDS and sepsis. Lancet Respir Med 2014;2(12):1016-1026

108 Liechty KW, MacKenzie TC, Shaaban AF, et al. Human mesenchymal stem cells engraft and demonstrate site-specific differentiation after in utero transplantation in sheep. Nat Med 2000;6 (11):1282-1286

109 Wong AP, Dutly AE, Sacher A, et al. Targeted cell replacement with bone marrow cells for airway epithelial regeneration. Am J Physiol Lung Cell Mol Physiol 2007;293(03):L740-L752

110 Ortiz LA, Dutreil M, Fattman C, et al. Interleukin 1 receptor antagonist mediates the antiinflammatory and antifibrotic effect of mesenchymal stem cells during lung injury. Proc Natl Acad Sci U S A 2007;104(26):11002-11007

111 Danchuk S, Ylostalo JH, Hossain F, et al. Human multipotent stromal cells attenuate lipopolysaccharide-induced acute lung injury in mice via secretion of tumor necrosis factor- $\alpha$-induced protein 6 . Stem Cell Res Ther 2011;2(03):27

112 Ionescu L, Byrne RN, van Haaften T, et al. Stem cell conditioned medium improves acute lung injury in mice: in vivo evidence for stem cell paracrine action. Am J Physiol Lung Cell Mol Physiol 2012;303(11):L967-L977

113 Fang X, Abbott J, Cheng L, et al. Human mesenchymal stem (stromal) cells promote the resolution of acute lung injury in part through lipoxin A4. J Immunol 2015;195(03):875-881

114 Fang X, Neyrinck AP, Matthay MA, Lee JW. Allogeneic human mesenchymal stem cells restore epithelial protein permeability in cultured human alveolar type II cells by secretion of angiopoietin-1. J Biol Chem 2010;285(34):26211-26222

115 Goolaerts A, Pellan-Randrianarison N, Larghero J, et al. Conditioned media from mesenchymal stromal cells restore sodium transport and preserve epithelial permeability in an in vitro model of acute alveolar injury. Am J Physiol Lung Cell Mol Physiol 2014;306(11):L975-L985

116 Lee JW, Fang X, Gupta N, Serikov V, Matthay MA. Allogeneic human mesenchymal stem cells for treatment of $\mathrm{E}$. coli endotoxin-induced acute lung injury in the ex vivo perfused human lung. . Proceedings of the National Academy of Sciences 2009: pnas-0907996106

117 McAuley DF, Curley GF, Hamid UI, et al. Clinical grade allogeneic human mesenchymal stem cells restore alveolar fluid clearance in human lungs rejected for transplantation. Am J Physiol Lung Cell Mol Physiol 2014;306(09):L809-L815

118 Raffaghello L, Bianchi G, Bertolotto M, et al. Human mesenchymal stem cells inhibit neutrophil apoptosis: a model for neutrophil preservation in the bone marrow niche. Stem Cells 2008; 26(01):151-162

119 Laffey JG, Matthay MA. Fifty years of research in ARDS. Cellbased therapy for acute respiratory distress syndrome. Biology and potential therapeutic value. Am J Respir Crit Care Med 2017; 196(03):266-273

120 Islam MN, Das SR, Emin MT, et al. Mitochondrial transfer from bone-marrow-derived stromal cells to pulmonary alveoli protects against acute lung injury. Nat Med 2012;18(05):759-765

121 Phinney DG, Di Giuseppe M, Njah J, et al. Mesenchymal stem cells use extracellular vesicles to outsource mitophagy and shuttle microRNAs. Nat Commun 2015;6:8472

122 Jackson MV, Morrison TJ, Doherty DF, et al. Mitochondrial transfer via tunneling nanotubes is an important mechanism by which mesenchymal stem cells enhance macrophage phagocytosis in the in vitro and in vivo models of ARDS. Stem Cells 2016;34(08):2210-2223

123 Zhu YG, Feng XM, Abbott J, et al. Human mesenchymal stem cell microvesicles for treatment of Escherichia coli endotoxininduced acute lung injury in mice. Stem Cells 2014;32(01): 116-125

124 Morrison TJ, Jackson MV, Cunningham EK, et al. Mesenchymal stromal cells modulate macrophages in clinically relevant lung injury models by extracellular vesicle mitochondrial transfer. Am J Respir Crit Care Med 2017;196(10):1275-1286

125 Wilson JG, Liu KD, Zhuo H, et al. Mesenchymal stem (stromal) cells for treatment of ARDS: a phase 1 clinical trial. Lancet Respir Med 2015;3(01):24-32

126 Matthay MA, Calfee CS, Zhuo H, et al. Treatment with allogeneic mesenchymal stromal cells for moderate to severe acute respiratory distress syndrome (START study): a randomised phase 2a safety trial. Lancet Respir Med 2019;7(02):154-162 